\title{
Comparison and correction of element measurements using qualitative and quantitative $X$-ray fluorescence in lacustrine sediments: A case study of Lake Hurleg
}

\author{
Aiying Cheng ${ }^{1,2, *}$, Junqing Yu ${ }^{1,2}$, Chunliang Gao ${ }^{1,2}$, Lisha Zhang ${ }^{1,2}$ \\ ${ }^{1}$ Key Laboratory of Comprehensive and Highly Efficient Utilization of Salt Lake Resources, Qinghai Institute of Salt Lakes, Chinese \\ Academy of Sciences, Xining 810000, China; \\ ${ }^{2}$ Qinghai Provincal Key Laboratory of Geology and the Environment of Salt Lake, Xining 810008, China
}

\begin{abstract}
Using an X-ray Fluorescence (XRF) core scanner with nondestructive and successive, the chemistry features of lacustrine sediment can be measured directly. This method of XRF core scanner measurements has been widely applied to core sediment analysis but uncertain of the precision and accuracy. Comparison of intensities obtained by XRF core scanning and the concentration measured by conventional $\mathrm{X}$-ray Fluorescence, indicates effects of physical properties varied from different elements on elemental intensities in the lacustrine sediments of a core from Lake Hurleg in the northeastern Tibetan Plateau. Correlation among elements $\mathrm{Ti}$ and $\mathrm{Sr}$ between the two measurement methods of the XRF and the conventional XRF is high. Using the intensity of $\mathrm{Cl}$ as an indicator of water content, the element intensities of $\mathrm{Ti}$ and $\mathrm{Sr}$ in the core samples is corrected. But the correlation coefficients of $\mathrm{Ti}$ and $\mathrm{Sr}$ is litter raised. The results show that XRF core scanning is a very useful tool for measuring element concentration in sediments particularly for high intensities elements.
\end{abstract}

\section{Introduction}

Lakes are very important for ecosystem, such as climate, tectonic human activities and so on. The important terrestrial records of environmental change over a range of timescale, recording both catchment-scale dynamics and regional climatic variability are preserved in lake sediments [1]. And lake sediments can provide long, continuous and high-resolution archives comparable to those from oceans and ice cores and the sedimentary records are sensitive to past variability in regional climate. And in most cases the changes of source from land can be transmitted to lake sediments. On the other hand, due to the Tibetan Plateau's relatively stable sedimentary environment and the relative ease with which, in such a comparatively pristine environment can be identified[2], the deep-water lacustrine sediments of this region are likely to have faithfully recorded, and are also able to serve as a global indicator of the presence of elements within the environment[3-5]. Therefore, a multi-proxy approach should be required to settle the various factors, which are influence sediment composition and thus environmental interpretation.

$\mathrm{X}$-ray fluorescence (XRF) is a well-established analytical technique for estimating the composition of sediments. In this first study of the elements of Lake Hurleg, samples from core KLK02 were investigated. In particular, we measured the element concentrations sedimentary layer in an attempt to analyze them and to evaluate whether or not they were veracity. A comparison of the analyzed data from both XRF core scaning and conventional quantitative XRF measurements aided geochemical and environmental reconstructions.

\section{Sample and methods}

\subsection{Study area}

Lake Hurleg $\left(37^{\circ} 17^{\prime} \mathrm{N}, 96^{\circ} 54^{\prime} \mathrm{E} ; 2817 \mathrm{~m}\right.$ above sea level) a freshwater lake and surrounded mostly by Quaternary lacustrine and alluvial deposits is located in the Qaidam Basin on the northeastern Tibetan Plateau[6]. The Qaidam Basin, surrounded by the Kunlun Mountains to the south, the Altun Mountains to the west and the Qilian Mountains to the north and east, is an area of $12000 \mathrm{~km}^{2}$. The average elevation of the basin surrounding mountains (an elevation of $>5000 \mathrm{~m}$ ) is $2800 \mathrm{~m}$., while the mean annual precipitation at nearby Delingha meteorological station (at $2982 \mathrm{~m}$ a.s.1.) is about $160 \mathrm{~mm}$ and is highly variable. The summer months has the most moisture falls as rain, and precipitation increases at about $45 \mathrm{~mm}$ per $100 \mathrm{~m}$ increase in elevation on the basis of seven stations in the region. So the actual precipitation at Lake Hurleg is likely $<100 \mathrm{~mm}$. Lake Hurleg is mainly fed by the Bayin River, the Balegen River and groundwater from the mountains to the north, and drains through Lianhu River into Lake Toson. The entire

\footnotetext{
* Corresponding author: * aycheng@isl.ac.cn
} 
catchment area is about $12600 \mathrm{~km}^{2}$, and the area is about $56.7 \mathrm{~km}^{2}$ of Lake Hurleg. Meteorological data indicate a $\sim 4^{\circ} \mathrm{C}$ of mean annual temperature, a $\sim 160 \mathrm{~mm}$ of mean annual precipitation mostly during the summer, and $\sim 2,000 \mathrm{~mm}$ of a mean annual potential evaporation during the period 1956-2004 from Delingha station (Fig.1).

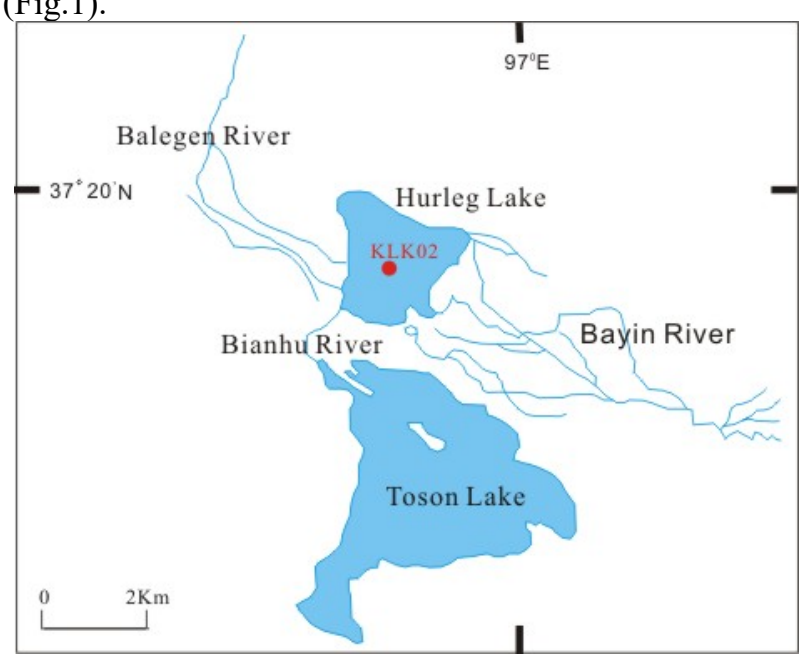

Figure 1. The map showing the catchment and the location of core KLK02 in Lake Hurleg.

\subsection{Sample collection}

The sedimentary environment of Lake Hurleg was reconstructed using data derived from sediment core KLK02 (Fig.1). The core was collected using Hammer gravity coring system. The 850 -mm-long sediment core (KLK02) close to the center of the lake was taken at Lake Hurleg in September 2014 from $7.2 \mathrm{~m}$ water depth using a custom-designed piston corer $(6 \mathrm{~cm}$ in diameter). The sediment cores were transported back to the laboratory in PVC pipes and described. And shortly thereafter, the cores were split in two halves lengthwise. We examined the visual macroscopic features of the core in detail in order to determine the different sedimentary facies. The core show successive with homogeneous lithology.

\subsection{Analytical methods}

Using an X-ray Fluorescence (XRF) core scanner, chemistry features of sediment core can be measured directly which does not destruct sediment surface nor split sediment cores. This method has been potentially and widely applied to core sediment analysis and collected of high-resolution chemical data from core profiles [7-9]. The high-resolution chemical data from core profiles can be rapidly collected from X-ray fluorescence (XRF) core scanning. The depth of surface sediment analyze by XRF core scanning generally does not exceed a few tens of microns. The step of analysis is set up to $1 \mathrm{~mm}$ in order to acquire a continuous record of elemental compositions along the sediment cores. The measurement time is 20 s for each individual step analysis. And then the core was subsampled at 1.5-centimeter intervals. Dried sediment samples was crushed in an agate mortar and pestle, and analyzed for the concentration measured by conventional X-ray Fluorescence using powdered. Overall, about fifty-eight samples were analyzed by Conventional X-ray Fluorescence from core

\section{Results and analysis}

The conventional quantitative XRF analysis of elements within the selected Lake Hurleg sedimentary core samples $(n=58)$. The mean contents of the elements $\mathrm{Ti}$ and $\mathrm{Sr}$ in Lake Hurleg's sediments were the highest and the mean concentrations of $\mathrm{Ti}$ and $\mathrm{Sr}$ in the sedimentary samples were $1806 \mathrm{ppm}$ and $1687 \mathrm{ppm}$ respectively. Scanning X-ray fluorescence for major element chemical analysis was carried out on archive-core halves for KLK02 core from Lake Hurleg. The X-ray fluorescence (XRF) core scanner can provide a high-resolution record (every $1 \mathrm{~mm}$ ) of geochemical variation and the XRF core scanner results were expressed hereafter as element peak intensities by counts per second (cps). Element concentrations were not directly available from the XRF measurements and the processing software. The areas of the element peaks provided an indication of the relative concentrations of each element [10].

The data derived from the conventional XRF were correlated with XRF core scanning results. The correlation coefficient of $\mathrm{Ti}$ and $\mathrm{Sr}$ was 0.5 and 0.66 respectively (Fig.2). During the XRF core scanning process, any measurements would relatively heavily influenced by the energy levels of any X-ray source, as well as by the physical and chemical properties of the sediment [11-13]. The XRF core scanning results from studies of marine sediments would necessarily have been affected by the moisture content of the core, as well as the particular core's carbonate content, particle composition and any changes in the density and porosity of its mineral composition. Of these drawbacks, high water content could be seen as the most negative influence on the accuracy of any results, as a high water content would inevitably reduce the density of any elements scanned using the XRF method [14-16]. Nonetheless, the accuracy of such XRF scanning can be improved by making scientifically-based water content corrections. The strong chemical activity, and hence density, of the element $\mathrm{Cl}$ plays an important part in any sedimentary composition, meaning that this intensity can be used as an alternative indicator of the extent of any changes in moisture content in a sedimentary core. The higher the water content, the higher the $\mathrm{Cl}$ density. Measurements resulting from XRF scanning can therefore potentially be calibrated using the elemental intensity of $\mathrm{Cl}[17,18]$. Out results showed a clear correlation between XRF scanning and conventional XRF data, and that the correlation coefficient between the calculated results for each element and the conventional XRF improved after water/Cl correction. The correlation coefficient of $\mathrm{Ti}$ and $\mathrm{Sr}$ was 0.55 and 0.72 (Fig.2). It demonstrated that water content exerted little impact upon the XRF scanning results of element Ti and $\mathrm{Sr}$ in Lake Hurleg. 

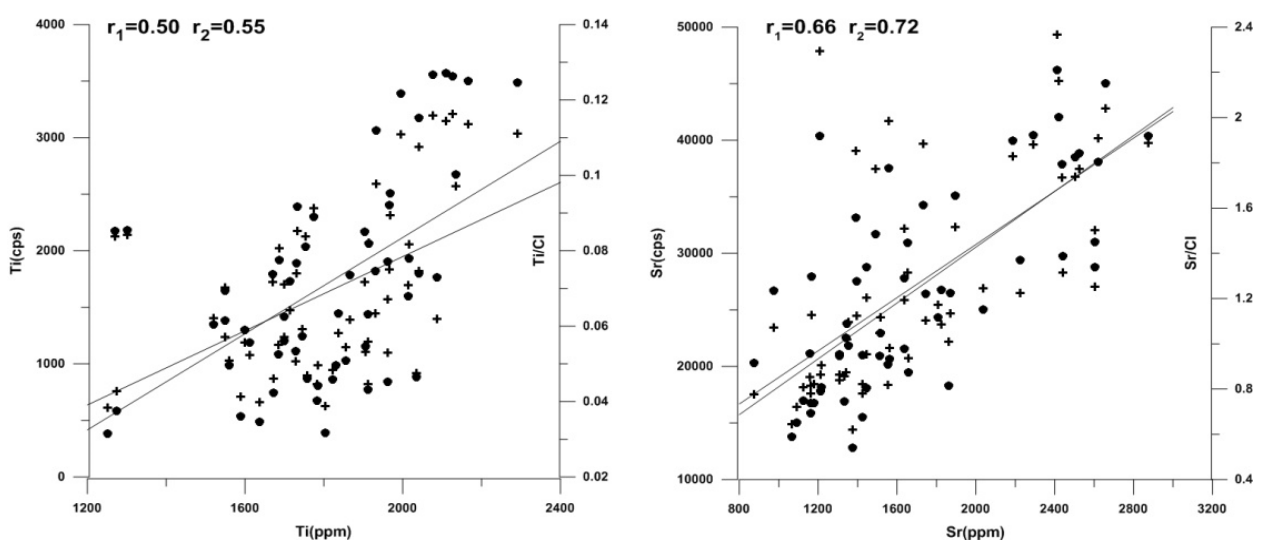

Figure 2. Correlations between XRF elemental intensity and conventional XRF elemental concentration (+: non-corrected; • water-corrected)

In the sections extracted from core KLK02, the trends and ranges exhibited by element $\mathrm{Ti}$ and $\mathrm{Sr}$ contents appeared close to those found when statistical regression was applied to the conventional XRF results. And it showed the higher comparisons between the concentrations derived from conventional XRF measurements and those after water/Cl correction using

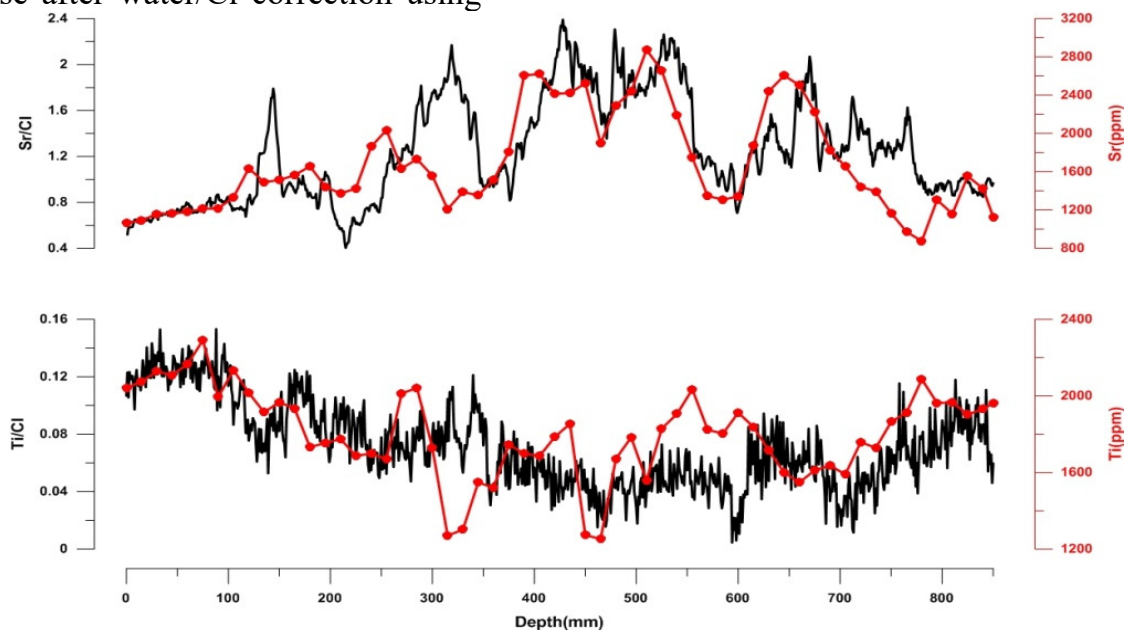

Figure 3. Comparisons between the concentrations derived from conventional XRF measurements and those calculated using XRF core scanning

\section{Conclusion}

When comparing this method with qualitative XRF core scanning analysis, it became clear that the results gained using these two different analytical methods were significantly comparable, especially when water content correction techniques were applied to the XRF scanning results. Correlation analysis of the two datasets XRF scanning results and another from conventional XRF measurements indicated that the element $\mathrm{Ti}$ and $\mathrm{Sr}$ fairly well and water content had little influence based on Cl-calibrated. This would suggest that interference of water content in core samples needed to be calibrated depending on the element. This indicated that, combined with the conventional XRF method, the XRF core scanning method can be a useful tool for establishing the contents of $\mathrm{Ti}$ and $\mathrm{Sr}$ in lacustrine sediments.
XRF core scanning (Fig.3). This was especially true when looking at the accuracy of such ranges in element content. This combined methodology can therefore go some way to satisfying the need for an accurate, high-resolution analysis of both the paleoclimate and the paleoenvironment. 
Mountains, northeastern Tibetan Plateau, inferred from amulti-proxy lake record. Palaeogeogr. Palaeoclimatol. Palaeoecol, 267(1-2): 59-76.

3. Jin, Z.D., Han, Y.M., Chen, L., (2010) Past atmospheric $\mathrm{Pb}$ deposition in Lake Qinghai, northeastern Tibetan Plateau. J. Paleolimnol, 43(3):551-563.

4. Mischke, S., Herzschuh, U., Massmann, G., Zhang, C.J., (2007) An ostracod-conductivity transfer function for Tibetan lakes. J. Paleolimnol., 38(4):09-524.

5. Zhang, Q.G., Kang, S.C., Wang, F.Y., Li, C.L., Xu, Y.W., (2008) Major ion geochemistry of Nam Co Lake and its sources, Tibetan Plateau. Aquat. Geochem., 14(4):321-336.

6. Yi, X., Yang, D., Xu, W., (1992) China regional hydrogeology survey report-Toson Lake (in Chinese), 1:200,000, Map J-47-[25], Daidam Integrative Geol. Surv., Golmud, China.

7. Cheburkin, A. K., Shotyk, W., (1996) Double-Plate Sample Carrier for a Simple Total Reflection X-Ray Fluorescence Analyser. X Ray Spectrometry, 25(4):175-178.

8. Koinig, K. A., Shotyk, W., André F. Lotter, Ohlendorf, C., Sturm, M., (2003) 9000 years of geochemical evolution of lithogenic major and trace elements in the sediment of an alpine lake-the role of climate, vegetation, and land-use history. Journal of Paleolimnology, 30(3): 307-320.

9. Mayr, C., Fey, M., Haberzettl, T., Haberzettl, T., Janssen, S., Lu"cke, A., Maidana, N.I., Ohlendorf, C., Frank Scha“bitz, F., Schleser, G.H., Struck, U., Wille, M., Zolitschka, B., (2005) Paleoenvironmental changes in southern Patagonia during the last millenium recorded in lake sediments from Laguna Azul (Argentina). Palaeogeography Palaeoclimatology Palaeoecology, 228(3):203-227.

10. Kazuyo, K., Olivier, C., Laurence,V., Luc,B., Edouard, B., (2011) The precession phase of hydrological variability in the western pacific warm pool during the past 400 ka. Quaternary ence Reviews, 30(25): 3716-3727.

11. Jansen, J., Van der Gaast, S., Koster, B., Vaars, A., (1998) CORTEX, a shipboard XRF-scanner for element analyses in split sediment cores. Marine Geology, 151(1-4):143-153.

12. Kulm, A.H., Freuden, T.T., Helmke, P., (2004) Reconstruction of paleoceanography off NW Africa during the last 40, 000 years: influence of local and regional factors on sediment accumulation. Marine Geology, 207(1-4): 209-224.

13. Ge, L., Lai, W., Lin, Y., (2004) Influence of and correction for moisture in rocks, soils and sediments on in situ XRF analysis. X-ray Spectrometry, 34(1):28-34.

14. Nakagawa, T., Gotanda, K., Haraguchi, T., Danhara, T., Yonenobu, H., Brauer, A., Yokoyama, Y., Tada, R., Takemura, K., Staff, R.A., Payne, R., Bronk Ramsey,
C., Bryant, C., Brock, F., Schlolaut, G., Marshall, M., Tarasov, P., \& Lamb, H., (2012) SG06, a fully continuous and varved sediment core from Lake Suigetsu, Japan: stratigraphy and potential for improving the radiocarbon calibration model and understanding of late Quaternary climate changes. Quaternary Science Reviews, 36:164-176.

15. Gordon, S., Achim, B., Marshall, M.H., Nakagawa, T., Staff, R.A., Ramsey, C.B., Lamb, H.F., Bryan, C.L., Naumann, R., Dulski, P., Brock, F., Yokoyama, Y., Tada, R., Haraguchi, T., (2014) Event layers in the Japanese Lake Suigetsu 'SG06' sediment core: description, interpretation and climatic implications. Quaternary Science Reviews, 83:157-170.

16. Franklin, R.L., Fávaro, D.I.T., Damatto, S.R., (2016) Trace metal and rare earth elements in a sediment profile from the Rio Grande Reservoir, Sa o Paulo, Brazil: determination of anthropogenic contamination, dating, and sedimentation rates. Journal of Radioanalytical \& Nuclear Chemistry, 307(1):1-12.

17. Tjallingii, R., Röhl, U., Kölling, M., Bickert, T., (2007) Influence of the water content on X-ray fluorescence core-scanning measurements in soft marine sediments. Geochem Geophys Geosyst, $8(2): 2-3$.

18. Weltje, G.J., Tjallingii, R., (2008) Calibration of XRF core scanners for quantitative geochemical logging of sediment cores: Theory and application. Earth and Planetary Science Letters, 27(3-4): 423438. 